\title{
Anti-commercial consumer rebellion: Conceptualisation and measurement
}

Received: 27th April, 2005

\section{Caroline Graham Austin}

is a PhD candidate, Marketing, at the Terry College of Business, University of Georgia.

\section{Christopher R. Plouffe}

is Assistant Professor, Marketing, at the Terry College of Business, University of Georgia.

\section{Cara Peters}

is Assistant Professor in the Management and Marketing Department at Winthrop University.

\begin{abstract}
Accounts indicate that consumers are increasingly concerned with the negative impact of business on global economics, politics, cultures and the environment. Many of these consumers point specifically to marketing policies and tactics as the primary impetus behind these negative influences and, perhaps because of this, many have begun to engage in some form of 'consumer rebellion'. This paper defines and conceptualises 'anti-commercial consumer rebellion' (ACR) as open and avowed resistance to institutionalised marketing practices. The paper reports the results of a scale development effort to measure anti-commercial consumer rebellion in the general population. The managerial implications of the ACR scale, study limitations and avenues for future research are discussed.
\end{abstract}

Keywords: anti-commercial consumer rebellion, resistance to marketing practices, scale development

\section{INTRODUCTION}

While all consumers have probably voiced their dissatisfaction with a particular business, product or service at one time or another, anecdotal accounts indicate that an increasing number of consumers are beginning to rebel more formally in the marketplace. This rebellion extends beyond traditional complaining and dissatisfied behaviour, as these individuals seem to be concerned with the effects of capitalism and marketing on global economics, politics, cultures and the environment.

Sociological definitions of rebellion are founded on resistance against institutionalised social structures. For example, McKee ${ }^{1}$ says, 'Rebellion takes the form of renouncing the previous goals and the social structure which legitimized it [the system] and then seeking to create a social structure in which a new set of cultural goals and institutionalized means are possible'. Anti-commercial consumer rebellion (ACR) is based on similar principles. As such, ACR is defined here as consumers' open and avowed resistance to institutionalised marketing practices.

Anti-commercial consumer rebellion 
has been associated with various sentiments and behaviours reported in the popular press. More acute forms of ACR include disruptive and even violent protest behaviours. For example, at the 1999 World Trade Organization (WTO) meeting in Seattle, protesters specifically targeted Nike, the Gap and Starbucks as being greedy and insensitive to local conditions, both in the manufacturing and marketing of their products, and caused several thousand dollars' worth of damage through acts of vandalism aimed at each of these companies. ${ }^{2}$ Every subsequent WTO meeting has met with protests along similar lines. ${ }^{3}$ While most consumers do not resort to such extreme behaviour to protest their displeasure with commercialisation and capitalism, academic researchers have begun to note increasing consumer concern with the pervasiveness of Westernised commercial influences on other cultures and ways of life - a phenomenon termed 'McDonaldization' by Ritzer. ${ }^{4}$

More benign but pervasive examples of ACR also exist in the popular press. In the USA, in a matter of weeks in 2003 , over 50 million consumers registered one or more of their telephone numbers on the national 'Do Not Call' list in an effort to avoid firms' telemarketing activities. ${ }^{5,6}$ While clearly not as damaging as the WTO protestors' behaviour, this case nevertheless illustrates that an important and widely relied-upon channel for marketing communication has been, for the most part, lost. Hence, it seems that ACR potentially spans a continuum of sentiments and behaviours. These range from relatively harmless, such as believing that the ubiquity of McDonald's has had significant, negative impact on global culture ${ }^{7}$ or refusing to shop at a megastore, such as Wal-Mart, on principle, ${ }^{8}$ to expensive, illegal and dangerous behaviours, such as arson. ${ }^{9}$

Despite the variance in the potential sentiments and behaviours associated with ACR, these accounts and the host of others like them underscore an important point which frames the context of this paper: even small acts of rebellion, if practised by enough people, could ultimately cause firms to sustain damages to their reputations, brands, market share and even fixed assets (among other important elements). Given the potential impact of such rebellion, the salience of better understanding this phenomenon seems readily apparent. This paper, therefore, attempts to conceptualise and measure ACR through the development of a scale which could be potentially valuable for managers who are attempting to deal with such phenomena in their industries. It should be noted that the unit of analysis in this work remains fixed at the level of the individual consumer, acknowledging, as the anecdotal accounts confirm, that rebellion can occur at the individual or collective (ie social movement) level. This paper holds that the topic should first be approached at the individual level to more generally identify the relevant aspects of anti-commercial rebellion to consumers. Future research should examine the construct for specific social movements.

Following a fourfold approach in the conceptualisation and initial empirical exploration of ACR, this paper develops as follows. First, using existing literature and anecdotal information as a guide, the ACR dimensions are conceptualised.

Secondly, exploratory work is undertaken in the form of principal components (or factor) analysis on one of two datasets. Thirdly, a confirmatory factor analysis is performed using the second unique dataset to validate the findings obtained in the exploratory work. Fourthly, a structural equation model is presented, which examines the predictive validity of ACR as it relates to need for uniqueness 
and materialism. The paper concludes by highlighting the implications and limitations of this work, suggesting directions for future research.

\section{THEORETICAL FOUNDATIONS}

The idea of widespread, endemic consumer resistance to the market began to take form in 1993 at the Association for Consumer Research's annual meeting, with a special session chaired by Peñaloza and Price. ${ }^{10}$ These authors overviewed some criticisms of marketing practices and suggested theoretical bases for such critiques. In the same session, Pollay ${ }^{11}$ discussed the advent of Adbusters Magazine, which had published six issues at that time, and Herrmann ${ }^{12}$ discussed boycotts and buyers' collectives (eg co-ops and consumer unions). Solidifying the existence of anti-commercial consumer rebellion, Dobscha ${ }^{13}$ observed and interviewed nine women who believe that marketing practices have led to a degradation of the quality of human life - 'waste, inefficiency, sickness, and materialism'. In response, these women consistently strive to minimise their contact with consumer culture. As anti-materialists, they resist advertising, creatively reuse products, buy or find second-hand goods and in general use as little as possible. Dobscha's subjects find the asymmetry of the marketplace disturbing, and attempt to correct perceived imbalances through significantly reduced consumption and non-traditional buyer behaviour in the marketplace.

In the span of less than a decade, many more researchers began to examine aspects of consumer rebellion. In 2002, Rumbo $^{14}$ followed up Pollay's original examination of Adbusters Magazine, finding that the magazine's readers try to maintain advertising-free psychic space for themselves in opposition to the hegemonic commercial 'clutter' that western free-market economies generate. Rumbo found that in general, dissenting voices have few outlets in such economic systems because the media themselves are commercialised, owing their existences to the continuing support of advertising dollars. Furthermore, marketers routinely co-opt and commodify resistant attitudes and behaviours, incorporating them into new marketing messages.

Kozinets ${ }^{15}$ conducted an ethnographic investigation into the Burning Man Festival, an experimental community festival held annually in the Black Rock Desert, Nevada. One of the main tenets of Burning Man is its 'no vending' rule, which extends to a ban on the display of brand names and logos. Consumers who attend Burning Man attempt to free themselves (at least for the week of the festival) from the constraints and demands imposed by the ubiquity of commercial interests. Kozinets finds that while it is impossible for consumers to become completely 'liberated' from the marketplace for any significant length of time, 'the illumination of taken-for-granted market logics, the flashes of inspiration, and the transformation of individuals and groups may be longer lasting'. ${ }^{15}$

Finally, Holt ${ }^{16}$ identified two competing theories that attempt to frame and explain ACR as a 'full-fledged social movement'. The first is Ozanne and Murray's ${ }^{17}$ theory of the 'reflexively defiant consumer', who sees the marketplace and marketing activities as social constructs rather than immutable forces of nature, and reacts to them as what they really are, rather than what most consumers perceive them to be. The second is Firat and Venkatesh's ${ }^{18}$ theory of 'liberatory postmodernism', in which consumers cobble together commercial cultural signifiers (ie brands) 
to create new meanings and social codes that are independent of the products' original intentions. Holt goes on to test these theories through a series of in-depth interviews, and concludes that anti-commercial consumers, rather than being rebellious, are actually conscious participants in the perpetuation of consumer culture, albeit as 'revolutionaries' who help to usher in new marketing paradigms. ${ }^{16}$

As can be seen above, the literature to date does an excellent job in identifying the existence of ACR as a genuine cultural and social phenomenon with multiple dimensions, ${ }^{19}$ but this pre-existing research fails to provide a concrete measurement tool for managers who are interested in assessing such sentiments and behaviours within the consumer population.

\section{THE DOMAIN OF ANTI-COMMERCIAL CONSUMER REBELLION}

Several themes consistently emerge in discussions and accounts surrounding ACR. Thus, based on previous qualitative research, the guiding supposition of this paper is that ACR is a multi-dimensional higher order construct. ${ }^{20}$ Reflection on the anecdotal, conceptual and qualitative literature has led to the recognition of four common themes. These themes guided the development of initial measurement items while also aiding in the identification of factors during the analysis of the survey data. Although they reflect rebellion triggers at the individual level, the themes themselves are macroscopic, and may have points of intersection. ${ }^{21}$

\section{Artifice}

Many consumers feel that marketing strategies, especially advertising tactics, are designed to be inherently misleading. The average consumer, who has probably grown up in a mediated environment exposed to thousands of commercial messages a week, has learned that product claims are often distorted. ${ }^{22}$ Qualitative research on consumer rebellion shows that consumers believe that many marketing practices are sleazy, purposely designed to subtly deceive consumers. ${ }^{23-25}$ Hence, the construct artifice captures consumer beliefs that marketers are constructing a deceitful 'plot' and using trickery to trap individuals into a consumption-oriented lifestyle.

\section{Avoidance}

Many environments and distinct constituencies are affected by commercial activities. Corporate malfeasance makes international headlines on a regular basis (eg Enron, WorldCom, Parmalat). At times, federal, state and local governments relax environmental, legal and tax standards to accommodate businesses, which is often perceived to be at the public's expense (eg www.georgialegalwatch.org). Indigenous cultural values are lost or denigrated as globalisation promotes homogeneous, primarily westernised, standards and norms around the world. ${ }^{26-28}$ Research by Dobscha, ${ }^{29}$ Herrmann $^{30}$ and Kozinets ${ }^{31}$ shows that consumer rebellion can manifest itself in avoidance behaviours. By intentionally withdrawing from doing business with 'unethical' companies, anti-commercial consumer rebels see themselves as taking a stand, on principle, to preserve that which they view as intrinsically valuable. ${ }^{32}$

\section{Cynicism}

Across the literature reviewed for this paper, a recurrent theme was that 
corporations and government work hand in hand to create the powerful phenomenon that is 'Big Business'. ${ }^{33-35}$ Individual consumers and workers can be crushed by this 'machine' if they try to resist its dictates, and perhaps even if they acquiesce. Businesses' alliances with public institutions (eg Chick-Fil-A's 'Partners in Education' programme with public schools), humanitarian organisations (eg McDonald's with UNICEF) and nonprofit organisations (eg the Bill and Melinda Gates Foundation) contribute to this outlook. Through such philanthropic activities, businesses can gain an edge over their competitors by leveraging political contacts to their advantage as well as by 'sneaking' into consumers' hearts. ${ }^{36,37}$ Many consumers are cynical with respect to businesses' real intentions and underlying motivations regarding broader societal wellbeing. Hence, cynicism captures consumers' jaded opinions about marketers and their practices. Put simply, consumer rebels doubt the integrity and distrust the motives of marketers.

\section{Manipulation}

Anti-commercial consumer rebels seem to believe that most people's mental and physical selves have been shaped from birth by marketing and market forces. Loosely regulated, laissez-faire capitalist systems tacitly facilitate businesses' manipulation of consumers' thoughts, feelings and behaviours, implicitly sanctioning less-than-ethical marketing tactics in order to generate sales. ${ }^{38}$ Anti-commercial consumers recognise this breakdown in trust between firms and consumers, and believe that businesses practice self-interest with guile, creating new products and then using marketing tactics to maximise consumer demand for these products (pharmaceutical companies have been particularly egregious in this regard ${ }^{39}$ ). Consumers often feel manipulated by these commercial activities. ${ }^{40-42}$ Therefore, the construct of manipulation captures the perceived exploitation of consumers by marketers and their practices. Anti-commercial consumer rebels believe that marketers have shrewdly managed the population to create demand and earn profits.

\section{POTENTIALLY SIMILAR, YET DIFFERENT, CONSTRUCTS}

Various studies have tackled several issues bordering on ACR. They range from measurements of frugality, ${ }^{43}$ socially responsible consumption behaviour, ${ }^{44,45}$ consumer alienation ${ }^{46-48}$ and consumer discontent with unethical business practices ${ }^{49,50}$ to anti-advertising attitudes, ${ }^{51-54}$ cooperation with 'green' marketing efforts ${ }^{55-58}$ and consumers' perceptions regarding their participation in boycotts. ${ }^{59}$ Furthermore, in 2002, an entire issue of the journal Psychology and Marketing was dedicated to the study of anti-consumption attitudes. Each of these papers is extremely micro-focused, however, looking at a single facet of the multi-dimensional higher order construct of ACR.

While important to the marketing literature, there is rationale as to why these existing scales are inappropriate and inadequate for understanding and exploring ACR. Several of these scales are only tangentially related to the domain of ACR, but, more importantly, none of these scales captures all that is inherent in a broadly conceived domain of ACR, as outlined in previous qualitative and conceptual studies. ${ }^{60-63}$ Furthermore, a simple comparison of the measures of these existing scales with the myriad ways in which consumers are genuinely disenchanted with marketing practices and their effects on consumer 
culture, as reported in the popular press, shows that there is an untapped domain that marketers need to address. At the same time, it is acknowledged that several of the existing scales mentioned above contain a few items that reflect a general displeasure with many of the marketing practices that underlie the attitudes and behaviours related to ACR.

\section{SCALE DEVELOPMENT}

Procedurally, the scale development reported here was greatly facilitated by the examples and guidelines of Richins and Dawson, ${ }^{64}$ Tian et al. ${ }^{65}$ and Spector ${ }^{66}$ in terms of item generation, and Churchill $^{67,68}$ and Gerbing and Anderson $^{69}$ in terms of data analysis and related issues. We closely followed the steps and prescriptions outlined by these scholars in developing the scale outlined below.

Considering examples from popular, managerial and academic sources, a pool of initial survey questions was generated, reflecting the four themes of artifice, avoidance, cynicism and manipulation. Along with this paper's authors, two marketing research graduate students participated in generating the question pool based on their own experiences and observations of ACR. Discussions among the research team resulted in an initial pool of 72 marketing-related statements, such as, 'I think marketers are sneaky'. Consumers' responses to statements were assessed using a 7-point scale, anchored from 'strongly disagree' to 'strongly agree' with a midpoint of 'neither disagree nor agree' ${ }^{70}$

For data collection, two distinct groups were recruited. First, the team garnered a sample of 600 undergraduate business students at a large US research university. Student participation was voluntary, and all students who completed the online survey were eligible to win a $\$ 100$ cash prize. In order to allow for more generalised findings ${ }^{71}$ as well as to have an additional, distinct respondent group to use for validation of the findings, a more demographically diverse population was sought as a second sampling frame.

Hence, 1,000 e-mail addresses from the same university were randomly selected from an alumni association database, and recipients of these e-mails were also offered the chance to win a $\$ 100$ cash prize upon the receipt of their completed surveys. Of the initial 1,000 e-mail addresses obtained by the research team, 630 proved valid (ie the e-mail addresses did not elicit 'bounce-back' messages when tested).

The survey design and execution procedures used were predicated upon Dillman's web survey protocol. ${ }^{72}$ The research team made all efforts to present the potential participants with high quality, appealing and easy-to-understand survey materials. For example, each e-mail message was personalised and contained a hyperlink which, when clicked, took the respondent directly to the secure survey website. The e-mail system and website were tested on a small scale and when no significant problems were noted, the first wave of the survey was launched. Survey completion information was available to the research team on a real-time basis, which precluded sending second- or third-wave e-mail reminders to subjects who had already responded to the survey. One week after the third and final wave of e-mail messages was sent out, all resultant information was downloaded from the website and data collection was closed.

In general, the response rates to the online survey were satisfactory (total $N=336)$ with normal demographic dispersion across the population. One area that will be discussed in greater 
Table 1: Exploratory factor analysis: Sub-dimensions of ACR

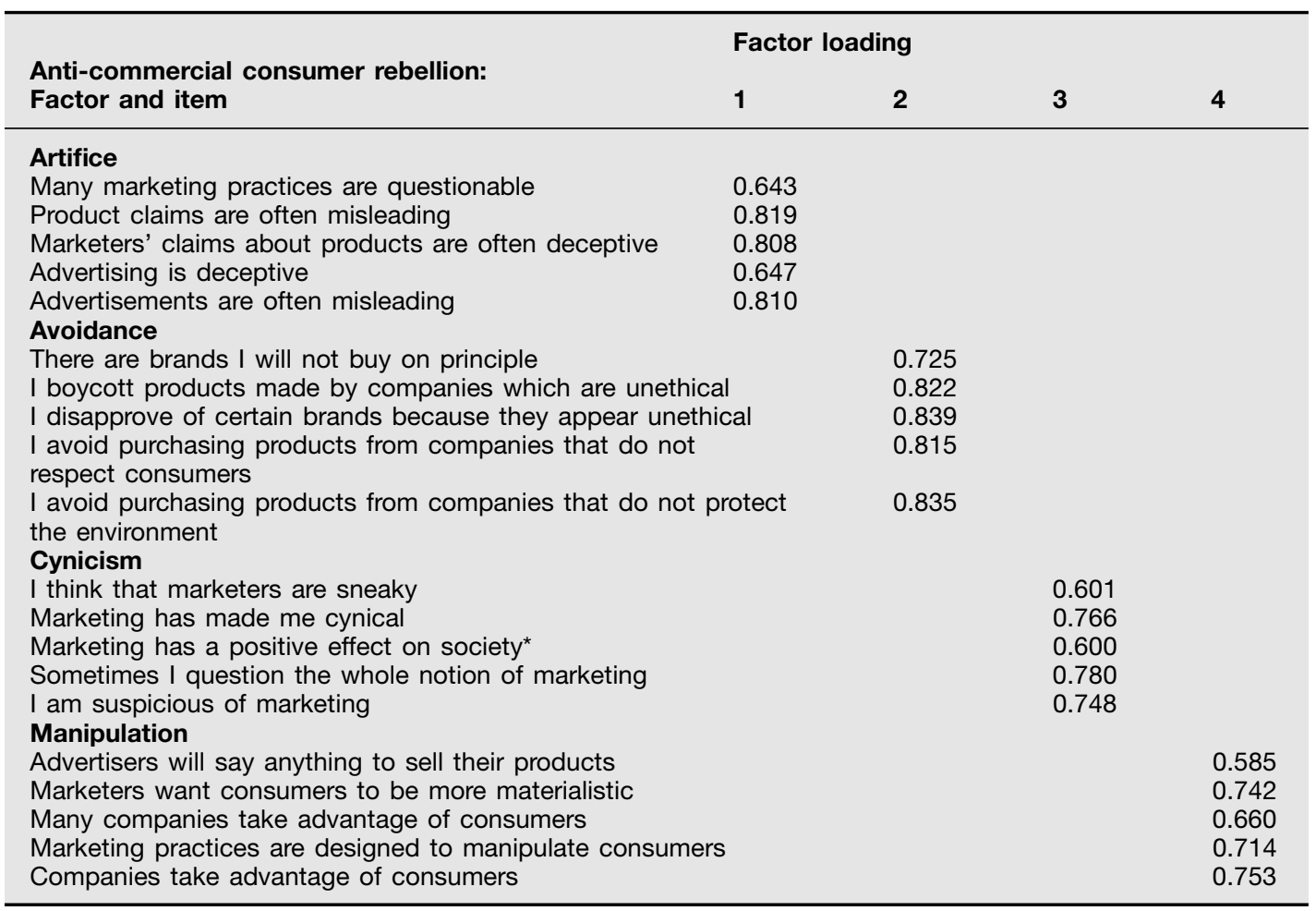

Note: Only loadings greater than 0.500 are shown. Asterisk indicates reverse-scored item.

detail later in the paper, however, is the education level of the survey's respondents. Because the sample populations were university students and alumni, everyone who responded to the questionnaire had at least some college education.

\section{CONSTRUCT VALIDITY: FACTOR ANALYSES}

The undergraduate and alumni data sets, respectively, were used to perform exploratory and confirmatory factor analyses. The data collected were normally distributed across both respondent groups. Descriptive statistics, distributional analyses and correlation and covariance matrices are not reported for reasons of parsimony, but are available to interested readers by contacting the lead author.

As the first major task, an exploratory factor analysis was conducted, following steps recommended by Hair et al. ${ }^{73}$ Principal components analysis of the data suggested that four factors seemed best at capturing the attitudinal and behavioural components inherent in ACR. While several other alternative factor analyses were performed, comparing slightly different assumptions about the data, only the results for the strongest 20-item solution are reported here. The four factors contained five items each (a remarkably symmetrical and elegant solution that needed no manipulation to achieve), and matched well with the original conceptualisation of ACR and were labelled accordingly. Table 1 reports the item loadings.

As the next major step in this research, a confirmatory factor analysis was conducted on the four factors identified in the exploratory work, this time employing the second, independent 
Table 2: Measurement model (CFA) estimates

\begin{tabular}{|c|c|c|c|}
\hline Factor and item & $\begin{array}{l}\text { Standardised } \\
\text { estimates }\end{array}$ & $t$-values & $\begin{array}{l}\text { Squared } \\
\text { multiple } \\
\text { correlations }\end{array}$ \\
\hline \multicolumn{4}{|l|}{ Artifice } \\
\hline Many marketing practices are questionable & 0.78 & 10.45 & 0.60 \\
\hline Product claims are often misleading & 0.78 & 10.55 & 0.61 \\
\hline Marketers' claims about products are often deceptive & 0.61 & 7.61 & 0.37 \\
\hline Advertising is deceptive & 0.74 & 9.72 & 0.54 \\
\hline $\begin{array}{l}\text { Advertisements are often misleading } \\
\text { Avoidance }\end{array}$ & 0.81 & 11.10 & 0.65 \\
\hline There are brands I will not buy on principle & 0.77 & 10.63 & 0.60 \\
\hline $\begin{array}{l}\text { I boycott products made by companies that are unethical } \\
\text { I disapprove of certain brands because they appear }\end{array}$ & 0.72 & 9.61 & 0.52 \\
\hline $\begin{array}{l}\text { unethical } \\
\text { I avoid purchasing products from companies that do }\end{array}$ & 0.86 & 12.56 & 0.74 \\
\hline $\begin{array}{l}\text { not respect consumers } \\
\text { I avoid purchasing products from companies that do }\end{array}$ & 0.84 & 12.12 & 0.71 \\
\hline $\begin{array}{l}\text { not protect the environment } \\
\text { Cynicism }\end{array}$ & 0.90 & 13.38 & 0.80 \\
\hline I think that marketers are sneaky & 0.71 & 9.30 & 0.50 \\
\hline Marketing has made me cynical & 0.67 & 8.68 & 0.45 \\
\hline Marketing has a positive effect on society ${ }^{*}$ & 0.81 & 11.30 & 0.66 \\
\hline Sometimes I question the whole notion of marketing & 0.77 & 10.43 & 0.59 \\
\hline $\begin{array}{l}\text { I am suspicious of marketing } \\
\text { Manipulation }\end{array}$ & \multicolumn{2}{|c|}{ Manipulation } & 0.61 \\
\hline Advertisers will say anything to sell their products & 0.66 & 8.37 & 0.43 \\
\hline Marketers want consumers to be more materialistic & 0.73 & 9.58 & 0.53 \\
\hline Many companies take advantage of consumers & 0.81 & 11.19 & 0.66 \\
\hline $\begin{array}{l}\text { Marketing practices are designed to manipulate } \\
\text { consumers }\end{array}$ & 0.73 & 9.54 & 0.53 \\
\hline Companies take advantage of consumers & 0.84 & 11.75 & 0.71 \\
\hline
\end{tabular}

Asterisk indicates reverse-scored item.

dataset (ie the alumni sample, $N=141$ ). We confirmed the model by restricting each scale item to load on the factor specified by the exploratory analysis. Table 2 shows that the items loaded onto their associated factors at a significant level. Other statistical indicators show that the model fits the 'real world' data set well by explaining where the variance in the data comes from, and how strongly each of the factors influences the overall construct of ACR. These results were guardedly interpreted as providing some evidence of the convergent validity associated with the ACR scale. ${ }^{74,75}$

\section{PREDICTIVE VALIDITY: HYPOTHESIS TESTS}

As a final step, Figure 1 represents the structural equation model estimated as a preliminary means of validating the ACR scale, complete with hypothesised relationships between constructs. In this model, the ACR scale was placed in a simple relational network with two conceptually related constructs materialism ${ }^{76}$ and need for uniqueness. ${ }^{77}$ These constructs have been previously measured in consumer behaviour literature, and statistically and conceptually robust surveys, instruments that measure materialism and need for uniqueness in the general population have been written and tested. The idea was to measure how strongly people feel each of these states of mind alongside ACR, and to determine whether there is any correlation between the three. In other words, to determine the strength of the relationships (if any) between ACR, materialism and consumers' need for uniqueness.

The materialism scale captures the 


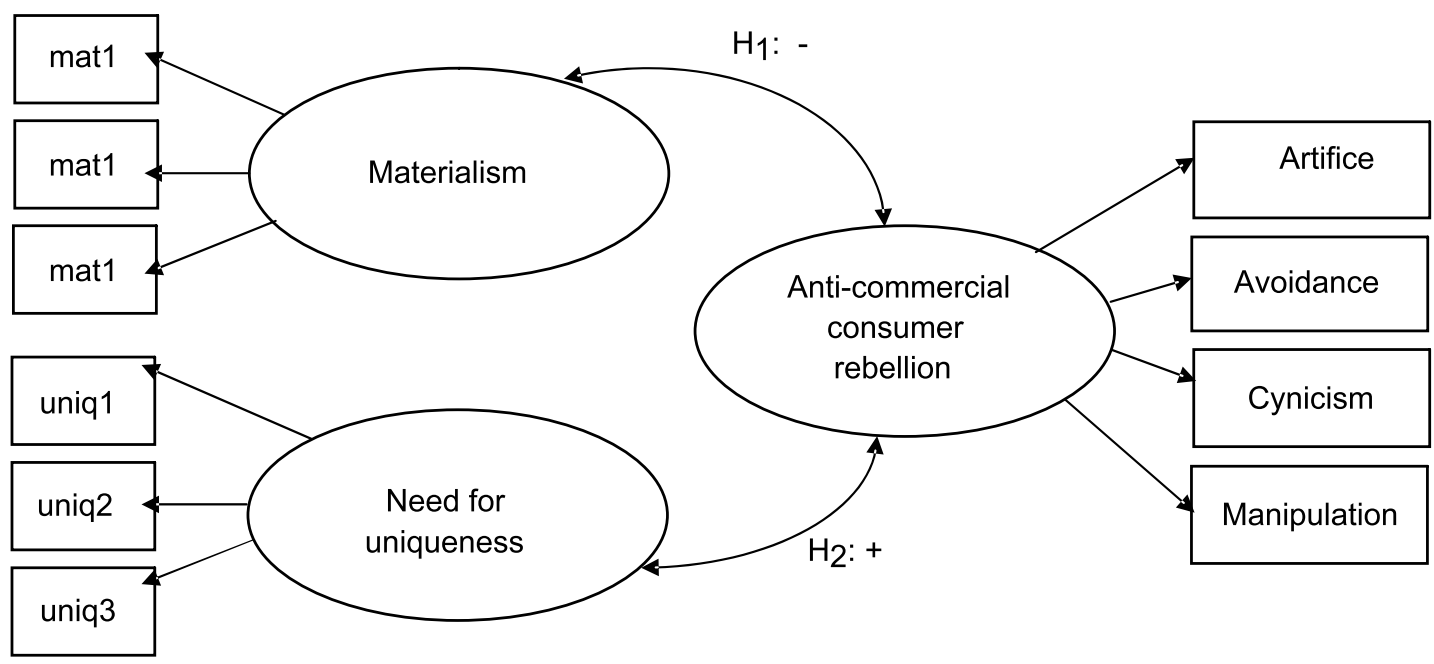

Note: All error and disturbance terms for this model have been omitted for the sake of clarity and space. Correlations among identified latent variables are also not included.

Figure 1 Hierarchical model for anti-commercial consumer rebellion, materialism and need for uniqueness

value placed on the acquisition of material objects ${ }^{78,79}$ and has three sub-dimensions: acquisition centrality, the role of acquisition in happiness and the role of possessions in defining success. ${ }^{80}$ Research indicates that materialism is inversely related to consumer wellbeing. For example, Belk ${ }^{81,82}$ found that materialism leads to non-generosity, envy, greed and overall dissatisfaction with life. Furthermore, Richins and Dawson ${ }^{83}$ show that materialism has a negative impact on satisfaction in various life domains (eg family, friends, fun, work, etc). To unpack the negative relationship between materialism and consumer wellbeing, Burroughs and Rindfleisch ${ }^{84}$ use a conflict values approach. These authors argue that individually oriented material values tend to conflict with collectively oriented family and religious values, and such inconsistency creates a psychological tension that reduces an individual's overall wellbeing.

Many of Dobscha's ${ }^{85}$ consumer rebels intuitively recognise the negative impact of materialism on life, culture and the environment, and they use this knowledge to rationalise their rebellious attitudes and behaviour toward marketers and the larger marketplace. Kozinets ${ }^{86}$ attendees at the Burning Man festival similarly report a desire to escape the materialism and greed of today's consumer culture as rationalisation for their retreat into the desert. Based on this previous research, it was anticipated that subjects who are very materialistic (ie scoring higher on Richins and Dawson's materialism scale) will be less likely to participate in ACR (ie scoring low on the ACR scale).

\section{$\mathrm{H}_{1}$ : There is a negative correlation between subjects' levels of materialism and anti-commercial consumer rebellion.}

The need for uniqueness is defined as an 'individual's pursuit of differentness relative to others that is achieved through the acquisition, utilisation, and disposition of consumer goods for the purpose of developing and enhancing one's personal and social identity'. ${ }^{87}$ The need for uniqueness scale has three 
sub-dimensions: creative choice counter-conformity, unpopular choice counter-conformity and avoidance similarity. ${ }^{88}$ Put simply, this scale captures an individual's desire to be different from the majority of consumers in the marketplace. Consumers who desire uniqueness want to create their own personal style, use products that differ from group norms (even to the point of garnering negative social approval) and avoid products that are common among the masses. According to Tian et al., ${ }^{89}$ these attitudes and behaviours cause individuals to place value on those material possessions that enhance their social difference, thus impacting on their personal and social identities.

Holt $^{90}$ finds in his qualitative study of consumer rebellion that his informants are not truly rebellious in a pure sociological sense, but rather are 'revolutionaries' because they consciously participate in consumer culture, although in unique, socially unconventional ways, and assist in ushering in new marketing paradigms. This previous research leads to the hypothesis that the type of independent thinker who desires to be different from the masses might also recognise, believe in and practice the principles of ACR. Thus, the 'counter-conformity motivation' that underlies a consumer's need for uniqueness ${ }^{91}$ may also shape that individual's perception of and desire to resist most traditional marketing practices and the homogenising influences of western-style capitalism that are embedded in mainstream consumer culture. This leads to the idea that the need for uniqueness will be positively related to an individual's level of ACR.

$\mathrm{H}_{2}$ : There is a positive correlation between subjects' levels of need for uniqueness and ACR.
To proceed, the data from both samples (student and alumni) were pooled, as structural equation modelling is relatively data intensive. ${ }^{92,93} \mathrm{Next}$, the data from the individual survey items were consolidated into factor means in order to make it more manageable for analysis. In other words, the 18 survey items for materialism were collapsed into three factor means (determining a single combined value for each factor: acquisition centrality, the role of acquisition in happiness and the role of possessions in defining success), the 31 items for need for uniqueness into three factor means (creative choice counter-conformity, unpopular choice counter-conformity and avoidance similarity) and the 20 ACR items into four factor mean values (artifice, avoidance, cynicism and manipulation). This step greatly reduced the number of variables included in the structural model from $69(18+31+20)$ to 10 $(3+3+4)$. These factor mean variables were then used to calculate the relationships between the three constructs tested in the structural equation model. $^{94-96}$

The findings for ACR and the ways it relates to both materialism and need for uniqueness are encouraging. As with the exploratory factor analysis described earlier, the model was compared with a competitor, a random chance, or null, model. This was done to determine if the model could be used to make more accurate predictions about consumer behaviour than would be yielded by simple guessing. After all, why bother with a calculator if a dartboard will work just as well? All of the statistical fit indices demonstrate that the model exceeds the null model for the same variables. Furthermore, the relationships tested between the three higher-order constructs are also statistically supported by the data. In this application, ACR 
Table 3: Cronbach's alpha values: ACR and comparison constructs

\begin{tabular}{llll}
\hline Alpha values & $\begin{array}{l}\text { Students only } \\
(\mathbf{N}=\mathbf{1 9 5})\end{array}$ & $\begin{array}{l}\text { Alumni only } \\
(\mathbf{N}=\mathbf{1 4 1})\end{array}$ & $\begin{array}{l}\text { Pooled sample } \\
(\mathbf{N}=\mathbf{3 3 6})\end{array}$ \\
\hline Overall ACR & 0.891 & 0.927 & 0.916 \\
Artifice & 0.887 & 0.896 & 0.895 \\
Avoidance & 0.881 & 0.865 & 0.879 \\
Cynicism & 0.802 & 0.857 & 0.840 \\
Manipulation & 0.811 & 0.870 & 0.840 \\
Overall NFU & 0.953 & 0.970 & 0.962 \\
uniq1 & 0.933 & 0.958 & 0.946 \\
uniq2 & 0.889 & 0.914 & 0.900 \\
uniq3 & 0.939 & 0.954 & 0.947 \\
Overall materialism & 0.871 & 0.865 & 0.876 \\
mat1 & 0.791 & 0.782 & 0.797 \\
mat2 & 0.745 & 0.797 & 0.774 \\
mat3 & 0.800 & 0.780 & 0.805 \\
\hline
\end{tabular}

Abbreviations: ACR; anti-commercial consumer rebellion; NFU, need for uniqueness.

and materialism are negatively correlated, while ACR and need for uniqueness are positively correlated, supporting both $\mathrm{H}_{1}$ and $\mathrm{H}_{2}$.

Table 3 shows that the four sub-dimensions of ACR all demonstrate reasonable psychometric properties as evidenced by their Cronbach's alpha values, as do the two comparison constructs, need for uniqueness and materialism. Path estimates representing how each item relates to its respective factor, as well as $t$-values for the measurement portion of the research model, are reported for ACR, need for uniqueness, and materialism in Table 4.

Table 4: Estimated path values for factor means model

\begin{tabular}{llr}
\hline Factors and items & $\begin{array}{l}\text { Standardised } \\
\text { estimates }\end{array}$ & t-values \\
\hline ACR & & \\
Artifice & 0.95 & 16.26 \\
Avoidance & 0.48 & 6.36 \\
Cynicism & 0.99 & 16.06 \\
Manipulation & 0.97 & 16.70 \\
Need for uniqueness & & \\
uniq1 & 0.96 & 16.18 \\
uniq2 & 0.83 & 16.67 \\
uniq3 & 0.95 & 16.71 \\
Materialism & & \\
mat1 & 0.99 & 14.59 \\
mat2 & 0.76 & 12.67 \\
mat3 & 0.69 & 9.28 \\
\hline
\end{tabular}

Abbreviations: ACR, anti-commercial consumer rebellion.

\section{DISCUSSION AND MANAGERIAL IMPLICATIONS}

In this initial development of the ACR scale, this paper has built upon the existing literature and in so doing, it is believed that it has added to marketers' ability to distinguish between and among those who are resisting the forces of marketing, materialism, commercialisation, and the widely pervasive culture of consumption that characterises most first-world societies. These independent-thinking, anti-commercial consumers might comprise a significant percentage of shoppers in the postmodern marketplace. As key stakeholders ${ }^{97}$ at the end of the commercial value chain, ${ }^{98}$ consumers who decide to quietly avoid (or loudly protest) products, brands, manufacturers, stores, service providers or other enterprises can have a major impact on whether or not organisations succeed or fail. In the simplest possible terms, without customers, there is no commercial enterprise. ${ }^{99,100}$ Hence, if managers can uncover, measure and moderate (or perhaps, more modestly, mitigate) sources of ACR in their target markets, they may, indirectly, accomplish two desirable goals: becoming more ethical in their business practices, while 
achieving greater congruency with emerging customer attitudes.

While increasing numbers of corporations, such as McDonald's, have departments solely devoted to corporate social responsibility and listening to consumers' voices related to ethical issues,${ }^{101}$ others have yet to implement the changes implied by their customers' protests, whether those protests are vocalised or silent (eg informal individual-level boycotts). The marketer's age-old axiom that 'the customer is always right' may not always be true, but in today's corporate arena, where 'customer loyalty' is more myth than reality, ${ }^{102,103}$ the increasingly resistant tendencies exhibited by consumers who identify with ACR are not likely to fade. As the academic literature and popular press anecdotes readily illustrate, ACR seems to drive real consumption decisions and behaviours that can damage firm assets and potential profits.

Thus, this study's results suggest that marketing managers have to be both proactive and reactive in ensuring honesty in their business practices in order to engage customers in today's marketplace. Proactively, the existence of ACR as a construct underscores the importance of practising sound business ethics and implementing socially responsible marketing programmes. Because of the expansive nature of ACR, marketing managers need to ensure that their organisations are creating corporate cultures that translate into honest, fair exchange with consumers across all domains of marketing. Taking the four P's as an example, businesses should ensure that they are selling high-quality products, pricing these products fairly, communicating accurately in their advertisements and distributing products through 'ethical retailers'. Reactively, marketers must have strategies designed to address consumer concerns effectively as they arise in the marketplace. For example, businesses need to have crisis management teams that respond appropriately and quickly to unethical business practices, socially irresponsible business behaviours and even consumer rumours.

A first potential limitation of this preliminary validation of the ACR scale pertains to the sampling frames employed in the survey. Specifically, the samples were convenience samples, which potentially limit the generalisability of the findings. Furthermore, every person who responded to the survey across both samples had completed at least high school, which is not true of the population at large. This may imply a systemic bias in the results; ${ }^{104}$ however, in partial defence of the two studied samples, sociologists, anthropologists and historians have all shown that people who first believe in (and later, actually participate in) broad-based social movements are traditionally among the most educated in society. ${ }^{105-107}$ Hence, it is believed that the sample selection choices were reasonable given the fact that this work represents an exploratory scale development effort.

A second potential limitation of this preliminary validation of the ACR scale relates to the issue of discriminant validity. As outlined earlier in this paper, there are a host of existing scales that appear to be at least tangentially related to ACR. Despite the fact that none of these scales seems to adequately capture the range and depth of sentiments and behaviours associated with such rebellion, future research needs to pursue the discriminant validity of ACR, proving that it is truly a unique construct that is different from any other reported in the marketing literature.

Despite these limitations, this research allows for future empirical work to assess who, how, when and why consumers 
rebel against certain commercial enterprises and marketing practices. A logical step in research pertaining to ACR might be to test the scale developed here on populations expected to score at its extremes (eg Green Party members and libertarians; organic farmers and hedge fund managers; high-school dropouts and MBA candidates). A variation on this approach would be to examine ACR cross-culturally and/or internationally, looking for interesting differences within and between diverse groups of consumers.

Beyond this, it is proposed that future research in this area be conducted to determine the antecedents that cultivate anti-commercial rebellion among consumers. Clearly, there are deeper social and psychological constructs that may drive such rebellion. One possible approach is to examine the psychological and social motivations of extreme anti-commercial rebels, such as arsonists, vandals and hackers. Another approach would be to examine ACR as a social movement, and perhaps as a paradigmatic shift in consumer thinking in general.

A final item on the agenda for future research is the examination of rapidly growing segments of the consumer population who are clearly engaging in anti-commercial rebellious behaviours. For example, peer-to-peer file sharing over the internet has illuminated the fact that large numbers of Americans some 60 million people, according to reporting on the CBS television news show 60 Minutes $^{108}$ — are willing to break fair-use laws. Consumers are sidestepping traditional distribution channels in order to freely obtain previously protected (and expensive) intellectual property including music, movies and software. ${ }^{109,110}$ It is posited that anti-commercial sentiments play no small part in people's willingness to engage in theft of this sort.
In conclusion, the empirical results reported in this exploratory work on the ACR scale seem promising and suggest that future testing and application in other empirical contexts may help to further ensure the construct's validity and reliability. There is significant convergent face validity between these findings, extant work reported in the literature and popular press coverage of ACR. Due to the increasing importance of the topic in the USA and around the world, this study's scale provides marketing practitioners with a tool to assess ACR - a first step toward preventing damage to a firm's intangible and tangible assets. Clearly, further exploration of ACR is necessary in both specific consumption contexts as well as in the marketplace in general.

\section{Acknowledgments}

All three authors gratefully acknowledge the generous financial support of the Coca-Cola Center for Marketing Studies at the University of Georgia. We have benefited immeasurably from the helpful comments provided by Robert Vandenberg and Srinivas Reddy on earlier versions of this paper. Finally, the assistance of Megan Lyle, Jonathan Lepisto, Candace McCain, Jeanne Wagner and Theresa Shen was appreciated during the conceptualisation and data gathering stages of this research.

\section{References}

1 McKee, J. (1969) 'Introduction to sociology', Holt, Rinehart, and Winston, New York, NY.

2 Lacayo, R. (1999) 'Rage against the machine: Despite, and because of, violence, anti-WTO protesters were heard', Time, Vol. 154, No. 24, pp. 34-39.

3 Tagliabue, J. (2001) 'Genoa Summit Meeting, the protesters: With eye on unequal world wealth, young Europeans converge on Genoa', New York Times, July 22 , p. A14.

4 Ritzer, G. (1996) 'The McDonaldization of society: An investigation into the changing character of contemporary social life', Pine Forge Press, Thousand Oaks, CA.

5 Goldstein, A. (2003) 'Do-not-call list supporters rally around registry', Knight Ridder Tribune Business News, 27 th September, p. 1.

6 Richtel M. (2003) 'After delays, US prepares to enforce do-not-call list', New York Times, 11th October, p. C 2.

7 Ritzer (1996) op. cit. 
8 Hirschman, A. (1970) 'Exit, voice, and loyalty: Responses to decline in firms, organizations, and states', Harvard University Press, Cambridge, MA.

9 Staff (2003) 'Possible ELF arson destroys four new homes', Associated Press, Available at: http://kcal9.com/localnews/localnewsla_story_ 262171941.html, last accessed 30th September, 2005.

10 Peñaloza, L. and Price, L. (1993) 'Consumer resistance: A conceptual overview', in McAlister, L. and Rothschild, M. (eds) Advances in Consumer Research, Vol. 20, pp. 123-128.

11 Pollay, R. (1993) 'Media resistance to consumer resistance: On the stonewalling of 'Adbusters' and Advocates', in McAlister, L. and Rothschild, M., Advances in Consumer Research, Vol. 20, p. 129.

12 Herrmann, R. (1993) 'The tactics of consumer resistance: Group action and marketplace exit', in McAlister, L. and Rothschild, M. (eds) Advances in Consumer Research, Vol. 20, pp. 130-134.

13 Dobscha, S. (1998) 'Life on the edge of the marketplace: The lived experience of consumer rebellion against marketing', in Alba, J. and Hutchison, J. (ed.) Advances in Consumer Research, Vol. 25, pp. 91-97.

14 Rumbo, J. (2002) 'Consumer resistance in a world of advertising clutter: The Case of Adbusters', Psychology \& Marketing, Vol. 19, No. 2, pp. 127-148.

15 Kozinets, R. (2002) 'Can consumers escape the market? Emancipatory illuminations from Burning Man', Journal of Consumer Research, Vol. 29, No. 1, pp. 20-38.

16 Holt, D. (2002) 'Why do brands cause trouble? A dialectical theory of consumer culture and branding', Journal of Consumer Research, Vol. 29, No. 1, pp. 70-90.

17 Ozanne, J. and Murray, J. (1995) 'Uniting critical theory and public policy to create the reflexively defiant consumer', The American Behavioral Scientist, Vol. 38, No. 4, pp. 516-525.

18 Firat, A. and Venkatesh, A. (1995) 'Liberatory postmodernism and the reenchantment of consumption', Journal of Consumer Research, Vol. 22, No. 3, pp. 239-267.

19 Holt (2002) op. cit.

20 Law, K. and Wong, C. (1999) 'Multidimensional constructs in structural equation analysis: An illustration using the job perception and job satisfaction constructs', Journal of Management, Vol. 25, No. 2, pp. 143-160.

21 Klein, K., Tosi, H. and Cannella, A. (1999) 'Multilevel theory building: Benefits, barriers, and new developments', Academy of Management Review, Vol. 24, No. 2, pp. 243-248.

22 Bond, J. and Kirshenbaum, R. (1997) 'Under the radar: Talking to today's cynical consumer', John Wiley \& Sons, New York, NY.

23 Dobscha (1998) op. cit.

24 Pollay (1993) op. cit.

25 Rumbo (2002) op. cit.

26 Klein, N. (2000) 'No space, no choice, no jobs, no logo: Taking aim at the brand bullies', Picador USA, New York, NY.
27 Ritzer (1996) op. cit.

28 Starr, A. (2000) 'Naming the enemy: Anti-corporate movements confront globalization', St. Martin’s Press, New York, NY.

29 Dobscha (1998) op. cit.

30 Herrmann (1993) op. cit.

31 Kozinets (2002) op. cit.

32 Sirsi, A., Ward, J. and Reingen, P. (1996)

'Microcultural analysis of variation in sharing of causal reasoning about behavior', Journal of Consumer Research, Vol. 22, No. 4, pp. 345-372.

33 Dobscha (1998) op. cit.

34 Herrmann (1993) op. cit.

35 Kozinets (2002) op. cit.

36 Rosen, E. (2000) 'The anatomy of buzz: How to create word-of-mouth marketing', Doubleday, New York, NY.

37 Silverman, G. (2001) 'The secrets of word-of-mouth marketing: How to trigger exponential sales through runaway word of mouth', Amacom: AMA Publications, New York, NY.

38 Mittal, B. (1994) 'Public assessment of television advertising: Faint praise and harsh criticism', Journal of Advertising Research, Vol. 34, No. 1, pp. 35-54.

39 Peterson, M. (2002) 'Madison Ave. plays growing role in drug research', New York Times, 22nd November.

40 Dobscha (1998) op. cit.

41 Herrmann (1993) op. cit.

42 Kozinets (2002) op. cit.

43 Lastovicka, J., Bettencourt, L., Hughner, R. and Kuntze, R. (1999) 'Lifestyle of the tight and frugal: Theory and measurement', Journal of Consumer Research, Vol. 26, No. 1, pp. 85-98.

44 Antil, J. (1984) 'Socially responsible consumption behavior: SRCB', Journal of Macromarketing, pp. 18-39.

45 Cowles, D. and Crosby, L. (1986) 'Measure validation in consumer research: A confirmatory factor analysis of the voluntary simplicity lifestyle scale', in Lutz, R. (ed.), Advances in Consumer Research, Vol. 13, pp. 392-297.

46 Allison, N. (1978) 'A psychometric development of a test for consumer alienation from the marketplace', Journal of Marketing Research, Vol. 15, No. 4, pp. 565-575.

47 Lambert, Z. (1980) 'Consumer alienation, general dissatisfaction, and consumerism issues: Conceptual and managerial perspectives', Journal of Retailing, Vol. 56, Summer, pp. 3-24.

48 Pruden, H., Shuptrine, F. and Longman, D. (1974) 'Alienation: Consumer alienation from the marketplace', Journal of the Academy of Marketing Science, Vol. 2, pp. 612-619.

49 Barksdale, H. and Darden, W. (1972) 'Consumer attitudes toward marketing and consumerism', Journal of Marketing, Vol. 36, pp. 28-35.

50 Lundstrom, W. and Lamont, L. (1976) 'The development of a scale to measure consumer discontent', Journal of Marketing Research, Vol. 13, No. 4, pp. 373-381.

51 Bearden, W., Hardesty, D., and Rose, R. (2001) 'Consumer self-confidence: refinements in 
conceptualization and measurement', Journal of Consumer Research, Vol. 28, No. 1, pp. 121-134.

52 Bush, A., Smith, R., and Martin, C. (1999) 'The influence of consumer socialization variables on attitude toward advertising: a comparison of African-Americans and Caucasians', Journal of Advertising, Vol. 28, No. 3, pp. 13-24.

53 Obermiller, C. and Spangenberg, E. (1998) 'On the origin and distinctiveness of skepticism toward advertising', Journal of Consumer Psychology, Vol. 7, No. 2, pp. 159-186.

54 Zavestoski, S. (2002) 'The social-psychological bases of anticonsumption attitudes', Psychology \& Marketing, Vol. 19, No. 2, pp. 149-165.

55 Easterling, D., Miller, S., and Weinberger, N. (1995) 'Environmental consumerism: a process of children's socialization and families' resocialization', Psychology $\mathcal{E}$ Marketing, Vol. 12, No. 6, pp. 531-550.

56 Polonsky, M. and Rosenberger III, P. (2001) 'Reevaluating green marketing: a strategic approach', Business Horizons, Vol. 44, No. 5, pp. 21-30.

57 Stone, G., Barnes, J., and Montgomery, C. (1995) 'ECOSCALE: a scale for the measurement of environmentally responsible consumers', Psychology $\mathcal{E}$ Marketing, Vol. 12, No. 7, pp. 595-612.

58 Zinkhan, G. and Carlson L. (1995) 'Green advertising and the reluctant consumer', Journal of Advertising, Vol. 24, No. 2, pp. 1-6.

59 Sen, S., Gurhan-Canli, Z., and Morwitz, V. (2001) 'Withholding consumption: a social dilemma perspective on consumer boycotts', Journal of Consumer Research, Vol. 28, No. 3, pp. 99-417.

60 Dobscha (1998) op. cit.

61 Kozinets (2002) op. cit.

62 Herrmann (1993) op. cit.

63 Holt (2002) op. cit.

64 Richins, M. and Dawson, S. (1992) 'A consumer values orientation for materialism and its measurement: scale development and validation', Journal of Consumer Research, Vol. 19, No. 3, pp. 303-316.

65 Tian, K., Bearden, W., and Hunter, G. (2001) 'Consumers' need for uniqueness: scale development and validation', Journal of Consumer Research, Vol. 28, No. 1, pp. 50-66.

66 Spector, P. (1992) 'Summated rating scale construction: an introduction', Sage, Newbury Park, CA.

67 Churchill, G. (1979) 'A paradigm for developing better measures of marketing constructs', Journal of Marketing Research, Vol. 16, No. 1, pp. 64-73.

68 Churchill, G. (1992) 'Better measurement practices are critical to better understanding of sales management issues', Journal of Personal Selling \& Sales Management, Vol. 12, No. 2, pp. 73-80.

69 Gerbing, D. and Anderson, J. (1988) 'An updated paradigm for scale development incorporating unidimensionality and its assessment', Journal of Marketing Research, Vol. 25, No. 2, pp. 186-192.

70 Spector (1992) op. cit.

71 Rentz, J. (1987) 'Generalizability theory: a comprehensive method for assessing and improving the dependability of marketing measures', Journal of Marketing Research, Vol. 24, No. 1, pp. 19-28.

72 Dillman, D. (2000) 'Mail and internet surveys: the tailored design method', 2nd edn, J. Wiley \& Sons, New York, NY.

73 Hair, J., Anderson, R., Tatham, R. and Black, W. (1995) 'Multivariate data analysis with readings', 4th edn, Prentice-Hall, Upper Saddle River, NJ.

74 Churchill (1979) op. cit.

75 Nunnally, J. (1978) 'Psychometric theory', 2nd edn., McGraw-Hill, New York, NY.

76 Richins and Dawson (1992) op. cit.

77 Tian, Bearden, and Hunter (2001) op. cit.

78 Burroughs, J. and Rindfleisch, A. (2002) 'Materialism and wellbeing: A conflicting values perspective', Journal of Consumer Research, Vol. 29, No. 3, pp. 348-370.

79 Richins, M. (1994) 'Special possessions and the expression of material values', Journal of Consumer Research, Vol. 21, No. 3, pp. 522-533.

80 Richins and Dawson (1992) op. cit.

81 Belk, R. (1984) 'Three scales to measure constructs related to materialism: Reliability, validity, and relationships to measures of happiness', in Thomas-Kinnear, J. (ed.), Advances in Consumer Research, Vol. 11, pp. 291-297.

82 Belk, R. (1985) 'Materialism: Trait aspects of living in the material world', Journal of Consumer Research, Vol. 12, No. 3, pp. 265-280.

83 Richins and Dawson (1992) op. cit.

84 Burroughs and Rindfleisch (2002) op. cit.

85 Dobscha (1998) op. cit.

86 Kozinets (2002) op. cit.

87 Tian, Bearden, and Hunter (2001) op. cit., p. 50.

88 Ibid.

89 Ibid.

90 Holt (2002) op. cit.

91 Tian, Bearden, and Hunter (2001) op. cit.

92 Bollen, K. (1989) 'Structural equations with latent variables', Wiley, New York, NY.

93 Bollen, K. and Long, J. (1993) 'Testing structural equation models', Sage Publications, Newbury Park, NJ.

94 Danes, J. (1984) 'Unidimensional measurement and structural equation models with latent variables', Journal of Business Research, Vol. 12, No. 3, pp. $337-352$.

95 Hair, Anderson, Tatham, and Black (1995) op. cit.

96 Hoyle, R. (1995) 'Structural equation modeling: Concepts, issues, and applications', Sage, Thousand Oaks, CA.

97 Freeman, R. (1984) 'Strategic management: A stakeholder approach', Pitman, Boston, MA.

98 Day, G. (1990) 'Market-driven strategy: Processes for creating value', The Free Press, New York, NY.

99 Clarkson, M. (1995) 'A stakeholder framework for analyzing and evaluating corporate social performance', Academy of Management Review, Vol. 20, No. 1, pp. 92-117.

100 Webster, F. (1992) 'The changing role of marketing in the corporation', Journal of Marketing, Vol. 56, No. 4, pp. 1-17. 
101 Hemphill, T. (1996) 'Beyond the bottom line: Putting social responsibility to work for your business and the world', Business and Society, Vol. 35, No. 1, pp. 123-129.

102 Henry, C. (2000) 'Is customer loyalty a pernicious myth?' Business Horizons, Vol. 43, No. 4, pp. 13-16.

103 Reinartz, W. and Kumar, V. (2000) 'On the profitability of long-life customers in a noncontractual setting: An empirical investigation and implications for marketing', Journal of Marketing, Vol. 64, No. 4, pp. 17-35.

104 Peterson, R. (2001) 'On the use of college students in social science research: Insights from a second-order meta-analysis', Journal of Consumer Research, Vol. 28, No. 3, pp. 450-461.

105 Fink, L., Leonard, S. and Reid, D. (1996) 'Intellectuals and public life: Between radicalism and reform', Cornell University Press, Ithaca, NY.

106 Fraser, S. and Freeman, J. (1997) 'Audacious democracy: Labor, intellectuals, and the social reconstruction of America', Houghton Mifflin, Boston, MA.

107 Wildemeersch, D., Finger, M. and Jansen, T. (1998) 'Adult education and social responsibility: Reconciling the irreconcilable?' P. Lang, New York, NY.

108 Stahl, L. (2003) 'Pirates of the internet', 60 Minutes, CBS television news documentary (Sunday 2nd November).

109 McGarvey, R. (2002) 'Long live P2P', EContent, Vol. 25, No. 3, pp. 18-25.

110 Roth, D. (2004) 'Pirates of the net: Catch us if you can', Fortune, Vol. 149, pp. 64-74.

111 Enders, C. (2001) 'A primer on maximum likelihood algorithms available for use with missing data', Structural Equation Modeling, Vol. 8, No. 1, pp. 128-141.

112 Bentler, P. (1998) 'Kurtosis, residuals, fit indices', available at: http://www.aime.ua.edu/cgi-bin/ wa?A1 =ind $9803 \& \mathrm{~L}=$ semnet, last accessed 30th September, 2005.

113 Mardia, K. (1970) 'Measures of multivariate skewness and kurtosis with applications', Biometrika, Vol. 57, No. 5, pp. 519-530.

114 Spector (1992) op. cit.

115 Ibid.

116 Bagozzi, R. and Youjae, Y. (1988) 'On the evaluation of structural equation models', Journal of the Academy of Marketing Science, Vol. 16, No. 1, pp 74-94.

117 Bollen, K. (1984) 'A new incremental fit index for general structural equation models', Sociological Methods and Research, Vol. 17, No. 2, pp. 303-316.

118 Bollen and Long (1993) op. cit.

\section{APPENDIX: DEMOGRAPHIC AND STATISTICAL INFORMATION}

Demographically, neither group contained any surprises. Approximately equal numbers of men and women from both groups responded to the survey. While the members of the undergraduate sample were primarily young $(95.5$ per cent between the ages 20-29 years, none older than 39 years), this was to be expected. The alumni sample contained excellent age dispersion; despite the survey having been administered online, almost one-third (30.4 per cent) of respondents were $\geq 50$ years of age. Among the student population, 12.6 per cent had already completed a baccalaureate degree; the remaining 87.4 per cent were working on their first degree. Of the alumni, 54.5 per cent had completed a bachelor's degree, while the remaining 45.5 per cent had finished graduate or professional school.

To impute the few missing data points in the data, the expectation maximisation (EM) procedure described by Enders ${ }^{111}$ was followed, using the algorithm provided by the PRELIS 2.50 software package. The covariance matrix generated by the EM algorithm was used to create and estimate the structural equation model in LISREL 8.54. In the complete dataset, item means ranged from 2.381 to 5.300 ; because scale items with maximum discriminant power were being examined, this range was to be expected. Skew and kurtosis $<2.0$ are within acceptable limits and the value for relative multivariate kurtosis was 1.088 , which is within normal limits. ${ }^{112,113}$ As all the data collected comes from a self-reported perceptual scale with possible values ranging from 1 to 7 , there were no outliers.

Initial data analysis and exploratory factor analysis was conducted using SPSS 11.0, while LISREL 8.54 was used for the confirmatory factor analysis.

Initially, while the 72 items in the ACR scale were adequately correlated with each other, the scale was considerably longer than desired, so 
following Spector, ${ }^{114}$ the most weakly correlated items were culled, and the overall strength of the scale was tested and retested until no items could be deleted that would raise coefficient alpha for the ACR scale. After culling the weakest items from the scale, the final 48 items had a coefficient alpha of 0.9565 . After conducting the exploratory factor analysis, the coefficient alpha was 0.91, which was considered acceptable. ${ }^{80}$

Exploratory factor loadings were well above the 0.35 recommended requirement. ${ }^{115}$

Table 2 shows that the items loaded onto their associated factors at a significant level $(t>2.0, p<0.001)$. For model fit, the Chi-square value was 259.36 $(p \leq 0.00, \mathrm{df}=164)$, with a root mean square error of approximation (RMSEA) of $0.061(p \leq 0.05)$, goodness of fit index $(\mathrm{GFI})=0.85$, normed fit index $(\mathrm{NFI})=0.86$, incremental fit index $(\mathrm{IFI})=0.94$ and comparative fit index $(\mathrm{CFI})=0.94$.

The calculation method used for the hierarchical factor model was maximum likelihood estimation (MLE) because with the relatively modest pooled sample size (ie $N=336$ ) and the normalcy this data set exhibited, MLE would give the most unbiased, consistent and efficient estimates of the path values selected for exploration.

The findings for ACR and the ways it relates to both materialism and need for uniqueness are encouraging. For the overall three-construct model captured in Figure 1, the minimum fit function Chi-square value is 123.51 ( $p \leq 0.001$, $\mathrm{df}=31)$, while the RMSEA value is $0.090(p \leq 0.001)$. Other measures of model are also reasonably robust (ie GFI $=0.94$, NFI $=0.90$, IFI $=0.93$ and CFI $=0.93) .{ }^{116-118}$ By contrast, the null hypothesis (the independence model with $45 \mathrm{df}$ ) yields a Chi-square value of 1297.67. All of the fit indices reported by LISREL demonstrate that the model, as tested, acceptably exceeds the independence (null) model for the same variables. Furthermore, the hypothesised correlations between constructs are also supported by the data. In this application, ACR and materialism are negatively correlated by a value of 0.24 ( $t$-value $=3.79$, thus supporting $\mathrm{H}_{2}$ ), while ACR and need for uniqueness are positively correlated by a value of 0.22 ( $t$-value $=3.54$, thus supporting $\mathrm{H}_{2}$ ). 